\title{
Effects of antibodies to oestrogens on implantation in ferrets
}

\author{
B. D. Murphy and R. A. Mead \\ Department of Biology, University of Saskatchewan, Saskatoon, \\ Saskatchewan, Canada S7N $0 W 0$ and \\ Department of Biological Sciences, University of Idaho, Moscow, Idaho 83843, U.S.A.
}

Oestrogen has been shown to be necessary to precipitate implantation in the rat and mouse (see review by Nalbandov, 1971). Progesterone alone can initiate implantation in most other mammals studied to date, and oestrogen either facilitates or has no effect on the nidatory process (Nalbandov, 1971; McLaren, 1971). Recent studies on hormonal control of implantation in ferrets (Wu \& Chang, 1972,1973 ) indicate that progesterone alone will support implantation (as indicated by uterine swellings) on Day 13 in ferrets ovariectomized on Days 8 or 10 . However, implantation was usually delayed in ferrets ovariectomized on Days 6 or 7 and treated with progesterone or progesterone + oestrogen.

This study was designed to investigate further the role of oestrogen in inducing implantation in ferrets by administration of specific antiserum to oestrogens during various periods of the preimplantation period. Oestradiol-17 $\beta$-hemisuccinate conjugated to bovine serum albumin was injected into sheep as previously described (Nett, Holtan \& Estergreen, 1973). The specificity of the antiserum was confirmed by testing its cross-reaction with various other steroids (Nett et al., 1973).

The efficacy of antiserum in binding oestradiol-17ß in the ferret was determined by injecting s.c. $0.5 \mathrm{ml}$ undiluted antiserum into two ferrets. After $18 \mathrm{hr}$, the ferrets were bled and the plasma tested for ability to bind oestrogen. Ferret plasma $(0.2 \mathrm{ml})$ diluted $1 / 10$ was capable of binding $78-80 \%$ of the $\left[{ }^{3} \mathrm{H}\right]$ oestradiol- $17 \beta(23,000 \mathrm{~d} / \mathrm{min})$ added, whereas plasma obtained from a ferret injected with normal sheep serum (NSS) bound only $6 \%$ of the $\left[{ }^{3} \mathrm{H}\right]$ oestradiol.

To test the ability of the antiserum to block an oestrogenic response in the ferret, six anoestrous female ferrets were injected s.c. with 100 i.u. PMSG followed by $0.5 \mathrm{ml}$ of either antiserum or NSS, the injections of which were repeated daily for 4 days. On the 5 th day, uteri were removed, blotted and weighed. Mean $( \pm$ S.E. $)$ uterine weight was significantly less $(t=2.27 ; P<0.05)$ in animals treated with antiserum $(192 \pm 8.4 \mathrm{mg} / \mathrm{g}$ body wt) when compared to that of animals treated with NSS ( $257 \pm 15.0 \mathrm{mg} / \mathrm{g}$ body wt).

The ability of this antiserum to prevent implantation in rats was demonstrated by daily s.c. administration of $0.25 \mathrm{ml}$ antiserum beginning at noon on the 2 nd day after mating. Control animals, injected with an equal amount of NSS on Days 2-7 had uterine swellings at autopsy on Day 7, but no swellings were observed in 6 animals treated with antiserum. Zona-free blastocysts were recovered from 3 of the antiserum-treated rats.

Female ferrets of unknown age were obtained from Dr John Gorham, U.S. Department of Agriculture, Pullman, Washington. The day of successful mating, confirmed by presence of spermatozoa in the vaginal smear, was designated Day 0 . In the first experiment, ferrets were injected either s.c. or i.p. with $1 \mathrm{ml}$ antiserum on Days 9-13 or Days 10-13. Control animals were likewise injected with NSS. In the second experiment, animals were injected s.c. with $0.5 \mathrm{ml}$ antiserum on Days 3-13 or Days 4-13. Laparotomy was performed on all animals on Day 14. The width and length of uterine swellings in the right horn of the uterus were observed and measured to the nearest $\mathrm{mm}$.

Every female in which spermatozoa were found in the vaginal smear exhibited uterine swellings on Day 14 (Table 1). Implantation was not therefore prevented by the antiserum to oestrogens in the doses used. A one-way analysis of variance was performed for the number of sites in the right horn, the length of sites, and the width of sites. For these analyses, data from three treatments were grouped: antiserum treatment beginning on Day 3 or 4; antiserum treatment beginning on Day 9 or 10; and control (NSS). 
Table 1. Effects of antiserum to oestradiol-17 $\beta$ on the mean ( \pm S.E.M.; range in parenthesis) number and size of implantation sites in the right uterine horns of ferrets at Day 14 post coitum

\begin{tabular}{|c|c|c|c|c|c|c|}
\hline \multirow[b]{2}{*}{ Treatment } & \multirow{2}{*}{$\begin{array}{c}\text { Day } \\
\text { treatment } \\
\text { started }\end{array}$} & \multirow{2}{*}{$\begin{array}{l}\text { No. of } \\
\text { amimals }\end{array}$} & \multicolumn{4}{|c|}{ Implantation sites } \\
\hline & & & & No. & Length (mm) & Width (mm) \\
\hline \multicolumn{7}{|c|}{ Anti-oestradiol-17 $\beta$} \\
\hline $0.5 \mathrm{ml} / \mathrm{day}$ & 3 & 3 & 3.0 & $\pm 0.8(1-4)$ & $6 \cdot 3 \pm 0 \cdot 3(5-8)$ & $6.2 \pm 0.6(5-8)$ \\
\hline \multirow[t]{2}{*}{$0.5 \mathrm{ml} / \mathrm{day}$} & 4 & 3 & $2 \cdot 8$ & $\pm 0.8(1-4)$ & $7 \cdot 5 \pm 0.9(5-9)$ & $6 \cdot 3 \pm 0.4(5-8)$ \\
\hline & Composite & 6 & 3.0 & $\pm 0.6(1-4)$ & $6.9 \pm 0.3(5-9)$ & $6.4 \pm 0.4(4-8)$ \\
\hline $1.0 \mathrm{ml} /$ day & 9 & 3 & $4 \cdot 0$ & $\pm 0.5(3-5)$ & $7 \cdot 7 \pm 0.3(7-9)$ & $6.3 \pm 0.2(5-7)$ \\
\hline \multirow[t]{2}{*}{$1.0 \mathrm{ml} /$ day } & 10 & 6 & $3 \cdot 4$ & $\pm 0.2(3-4)$ & $8 \cdot 1 \pm 0 \cdot 3(6-10)$ & $6.9 \pm 0.3(4-9)$ \\
\hline & Composite & 9 & $3 \cdot 6$ & $\pm 0 \cdot 2(3-5)$ & $8 \cdot 0 \pm 0.3(6-10)$ & $6.7 \pm 0.2(4-9)$ \\
\hline \multicolumn{7}{|c|}{ Normal sheep serum } \\
\hline $1.0 \mathrm{ml} / \mathrm{day}$ & 9 & 2 & $4 \cdot 5$ & $\pm 0.4(4-5)$ & $9.8 \pm 0.9(8-12)$ & $7 \cdot 2 \pm 0.6(6-9)$ \\
\hline \multirow[t]{2}{*}{$1.0 \mathrm{ml} / \mathrm{day}$} & 10 & 2 & $4 \cdot 0$ & \pm 0.0 & $10 \cdot 2 \pm 0.3(9-11)$ & $7 \cdot 8 \pm 0.1(7-8)$ \\
\hline & Composite & 4 & $4 \cdot 25$ & $\pm 0.2(4-5)$ & $10 \cdot 0 \pm 0.4(8-12)$ & $7 \cdot 6 \pm 0 \cdot 3(6-9)$ \\
\hline
\end{tabular}

Initiation of treatment with antiserum on Day 3 or 4 appeared to reduce the number of embryos implanting when compared with those in NSS-treated animals, and a slight reduction was noted between animals in which treatment was started on Day 3 or 4 and those in which treatment was started on Day 9 or 10. Thus antiserum administered daily may be preventing implantation of some of the embryos.

The length of uterine swellings exhibited a significant treatment effect $(F=19 \cdot 2$; d.f. 2 and 44 ; $P<0.001)$. Subsequent analysis by the least-significant difference test $(\mathrm{Li}, 1966)$ indicated that antiserum treatment beginning on either Day 3 or 4 or Day 9 or 10 significantly $(P<0.001)$ reduced swelling length. The width of uterine swellings showed less variability among treatments but approached significance, indicating a trend toward reduction of swelling width associated with antiserum treatment. The size differences of the uterine swellings suggest that the anti-oestrogen may have been slightly delaying the implantation process or slightly inhibiting either embryonic or uterine growth. This size reduction was most obvious in animals in which treatment was initiated on Day 3. While our experiment was not designed to distinguish between retardation of embryonic growth and inhibition of uterine reactions, the work of Wu \& Chang (1973) suggests that exogenous oestrogen does not facilitate embryonic development in ovariectomized ferrets. In the present study, the ferrets treated with antibodies to oestrogen gave birth at the normal time of 39-41 days, indicating that embryogenesis was not significantly delayed. The ferret uterus undergoes a size increase during the early postimplantation period (Enders \& Schlafke, 1972; Beck, 1974) and involves epithelial proliferation, hypertrophy of various cells, symplasma formation and uterine gland dilatation. Oestrogen may promote one or more of these responses and antiserum treatment would thus affect uterine growth.

It appears therefore that oestrogens are not obligatory for implantation in the ferret. Their absence is characterized only by a slight reduction in size of the uterine swellings. The report of Heap \& Hammond (1974) that total unconjugated oestrogens in peripheral plasma were not detectable $(<10 \mathrm{pg} / \mathrm{ml})$ in the majority of plasma samples examined during pregnancy or pseudopregnancy in the ferret, further suggests that oestrogens do not play an obligatory role in implantation in ferrets. Wu \& Chang (1973) speculate that, during the critical period of Days 6-8, ovarian steroids are secreted which modulate or facilitate the actions of progesterone and oestrogens, resulting in normal implantation in the ferret. Data from the present study do not refute this speculation.

This study was supported by grants A9743 from the National Research Council of Canada and a University of Saskatchewan President's Grant to B.D.M. We thank Dr John Gorham for donation of ferrets and DrV. L. Estergreen for his gift of antiserum to oestradiol-17ß. The technical assistance of Ms L. L. Potter is acknowledged. 


\section{References}

BrCK, F. (1974) The development of the maternal pregnancy reaction in the ferret. J. Reprod. Fert. 40, 61-69.

ENDERS, A.C. \& SchlaFKe, S. (1972) Implantation in the ferret: epithelial penetration. Am. J. Anat. 133, 291-316.

Heap, R.B. \& Hammond, J., JR (1974) Plasma progesterone levels in pregnant and pseudopregnant ferrets. J. Reprod. Fert. 39, 149-152.

LI, C.R. (1966) Statistical Inference. Edwards Bros, Ann Arbor.

MCLAREN, A. (1971) Blastocysts in the mouse uterus: the effect of ovariectomy, progesterone and oestrogen. J. Endocr. 50, 515-526.
Nalbandov, A.V. (1971) Endocrine control of implantation. In The Biology of the Blastocyst, pp. 383-392. Ed. R. J. Blandau. University of Chicago Press, Chicago.

NetT, T.M., Holtan, D.W. \& Estergreen, V.L. (1973) Plasma estrogens in pregnant and postpartum mares. J. Anim. Sci. 37, 962-970.

WU, J.T. \& CHANG, M.C. (1972) Effects of progesterone and estrogen on the fate of blastocysts in ovariectomized pregnant ferrets: a preliminary study. Biol. Reprod. 7, 231-237.

WU, J.T. \& CHANG, M.C. (1973) Hormonal requirement for implantation and embryonic development in the ferret. Biol. Reprod. 9, 350-355.

Received 1 July 1975 